\title{
Spatial patterns of glacier motion during a high-velocity event: Haut Glacier d'Arolla, Switzerland
}

\author{
Douglas Mair, ${ }^{1 *}$ Peter Nienow, ${ }^{2}$ Ian Willis, ${ }^{1}$ Martin Sharp ${ }^{3}$ \\ ${ }^{1}$ Department of Geography, University of Cambridge, Cambridge CB2 3EN, England \\ ${ }^{2}$ Department of Geography and Topographic Sciences, University of Glasgow, Glasgow G12 8QQ, Scotland \\ ${ }^{3}$ Department of Earth and Atmospheric Sciences, University of Alberta, Edmonton, Alberta T6G 2E3, Canada
}

\begin{abstract}
The surface motion of Haut Glacier d'Arolla, Switzerland, was monitored at a high spatial and temporal resolution. Data are analyzed to calculate surface velocities, surface strain rates and the components of the glacier force budget before, during and after an early melt season speed-up or "spring event". We investigate the extent to which variations in glacier motion can be attributed to hydrologically induced local forcing or to non-local forcing transmitted via horizontal stress gradients. Enhanced glacier motion is dependent on a change in the spatial distribution of areas of high drag across the glacier.
\end{abstract}

\section{INTRODUCTION}

Intra-annual variations in glacier motion are usually interpreted in terms of variations in basal motion controlled, at least in part, by fluctuations in subglacial water pressures (Iken and others, 1983; Iken and Bindschadler, 1986; Kamb and Engelhardt, 1987; Hooke and others, 1989; Iverson and others, 1995). High (low) subglacial water pressures will reduce (increase) the friction between the sole of the glacier and its bed, thereby reducing (increasing) the basal drag beneath the glacier and thus enhancing (reducing) basal motion.

Subglacial water pressures vary spatially (Fountain, 1994; Hubbard and others, 1995; Murray and Clarke, 1995) and temporally (Hooke and others, 1989; Fountain, 1993; Arnold and others, 1998; Gordon and others, 1998) because of the heterogeneous morphology of the drainage system and variable water inputs. These spatial and temporal variations in subglacial water pressures are likely to cause matching variations in basal drag (Fischer and others, 1999), causing variations in rates of basal motion. Spatial variations in basal motion will create horizontal gradients in stress in the overlying ice that influence glacier motion over an area larger than that which experiences direct basal forcing. Interpretation of glacier surface velocity variations as a function solely of locally defined variables, such as subglacial water pressure or local driving stress, may therefore be problematic (Jansson, 1995). To differentiate between motion due to the local influences of subglacial water pressure or driving stresses, and motion due to non-local influences transmitted by stress gradient coupling, it is necessary to study glacier dynamics over large areas with a high spatial and temporal resolution.

Analysis of changes in the balance of forces acting upon individual blocks of a glacier is a method by which all the

\footnotetext{
* Present address: Department of Earth and Atmospheric Sciences, University of Alberta, Edmonton, Alberta T6G 2E3, Canada.
}

factors controlling glacier velocity variations can be examined. In such force-budget analyses, basal drag is calculated from the driving stress, $\tau_{\mathrm{d}}$, shear stress at the sides and longitudinal stress up- and down-flow. The term "basal drag" is used here to define the resistive stress acting at the base of any defined "block" of the glacier. Force-budget analyses have been carried out over intra-annual time periods for just two glaciers: Storglaciären, Sweden (Hooke and others, 1989), and Columbia Glacier, Alaska, U.S.A. (Van der Veen and Whillans, 1993). Both studies identified spatial variations in basal drag. At Storglaciären, different high-velocity events throughout the summer were associated with different patterns of basal drag. Both studies suggested that spatial and temporal variations in basal drag might have been caused by variations in subglacial drainage conditions. Similarly, Iken and Truffer (1997) suggested that changes in subglacial drainage conditions between melt seasons may be responsible for the interannual variations in basal drag and surface motion observed at Findelengletscher, Switzerland. They invoked Weertman's (1964) idea that within a distributed drainage system, isolated and interconnected cavities may coexist. They noted that if more cavities are connected to the subglacial drainage system then a larger proportion of the glacier sole may be exposed to changes in water pressure within the drainage system, and thus a water-pressure change may have a larger effect on the sliding velocity. They also proposed that isolated cavities could damp variations in sliding velocities and act as "sticky spots" to impede sliding velocities during periods when water pressures within the interconnected cavity system were high. They recognized that interannual variations in functional relationships between observed water pressures and velocities were likely to be a consequence of variations in the "spatial extent of the interconnected cavity system" (Iken and Truffer, 1997, p. 335).

Thus, the three studies summarized above imply that hydrologically induced changes in the magnitude and spatial pattern of basal drag may influence variations in glacier surface velocity. The main limitations of these studies are: (1) basal drag was calculated at only a few locations due to the low spatial 
resolution of surface motion measurements; and (2) there was very little information about either the spatial configuration of the subglacial drainage system or the seasonal evolution of its morphology to aid interpretation of the basal drag calculations.

This paper presents the results of surface motion measurements made at Haut Glacier d'Arolla, Switzerland. Measurements were made at a high spatial and temporal resolution on the glacier tongue, where both the spatial configuration of the subglacial drainage system and the seasonal evolution in its morphology have been extensively studied (Sharp and others, 1993; Hubbard and others, 1995; Richards and others, 1996; Gordon and others, 1998; Nienow and others, 1998). Spatial patterns of surface velocity, surface strain rates and the components of the glacier force budget were calculated for periods before, during and after an early melt-season period of enhanced surface velocity (hereafter referred to as a "spring event"). Comparing these patterns with the spatial configuration of the subglacial drainage system enables us to assess the extent to which variations in glacier motion are due to hydrologically induced local forcing or to non-local forcing transmitted via stress gradients. The results contribute towards an improved understanding of how glacier motion is influenced by hydrologically induced changes in basal drag. This is an important component of ongoing attempts to develop and constrain glacier flow models that attempt to simulate full three-dimensional stress fields within glaciers and allow for feedbacks between basal motion and ice deformation (Blatter, 1995; Harbor and others, 1997; Hubbard and others, 1998).

\section{FIELD SITE}

Haut Glacier d'Arolla is located at the head of the Val d'Hérens, Valais, Switzerland (Fig. 1). The glacier consists of a $2.2 \mathrm{~km}$ long, north-south-trending tongue, approximately 750-800 m wide, fed by two separate firn basins. The glacier snout lies at an elevation of $2560 \mathrm{~m}$, while the main eastern basin and the tributary western basin rise to 3500 and $3325 \mathrm{~m}$, respectively. The centre-line length of the main glacier is about $4 \mathrm{~km}$ and the total glacier area is about $6.33 \mathrm{~km}^{2}$. The glacier has been the subject of an integrated study of glacier hydrology and meltwater quality which has led to a detailed understanding of how the subglacial drainage system varies in space and time (Richards and others, 1996). This makes it an ideal location for investigating the extent to which the spatial configuration and evolution in morphology of the subglacial drainage system affect spatial and temporal patterns of glacier surface motion.

\section{SUMMARY OF PREVIOUS HYDROLOGICAL RESEARGH}

Previous studies of the hydrology of Haut Glacier d'Arolla included work to: (1) determine the subglacial drainage configuration; and (2) determine the evolution of the morphology of subglacial drainage-system pathways. Since our interpretation of variations in spatial patterns of glacier motion is dependent upon an understanding of spatial variations in subglacial hydrology, it is necessary to summarize the main conclusions of this earlier research. Detailed description and discussion of the modelling and fieldwork strategies conducted can be found elsewhere (e.g. Sharp and others, 1993; Hubbard and others, 1995; Richards and others, 1996; Arnold and others, 1998; Gordon and others, 1998; Nienow and others, 1998).

The subglacial drainage network is dominated by two main preferential drainage axes (PDAs) (Sharp and others, 1993) (Fig. 2). Beneath the glacier tongue, the eastern PDA is located to the east of the valley centre line (i.e. east of approximately 606600 E) (cf. Fig. 2). The morphology of the drainage system within this eastern PDA evolves throughout the melt season from a hydraulically inefficient, distributed drainage axis to a hydraulically efficient, channelized axis (Gordon and others, 1998; Nienow and others, 1998). The seasonal onset of high-magnitude and diurnally variable surface runoff from impermeable, low-albedo ice surfaces plays a critical role in establishing major subglacial channels (Arnold

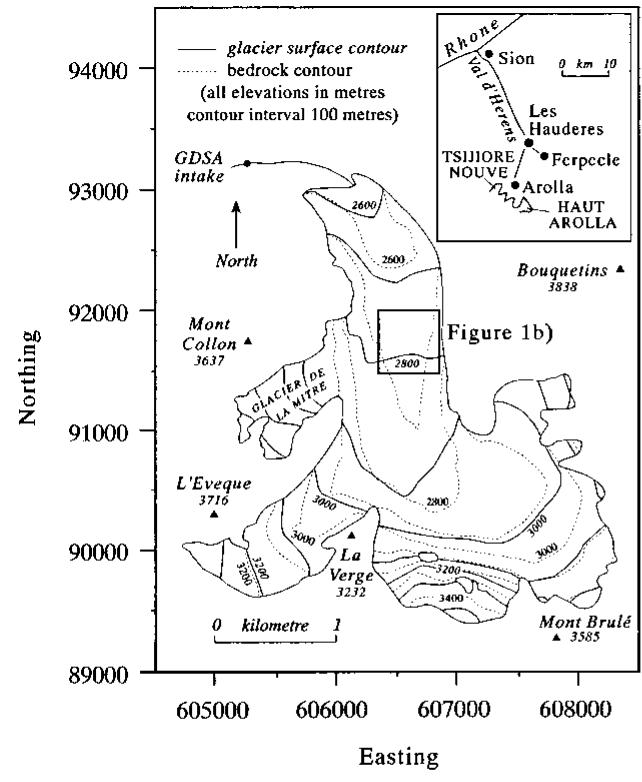

a

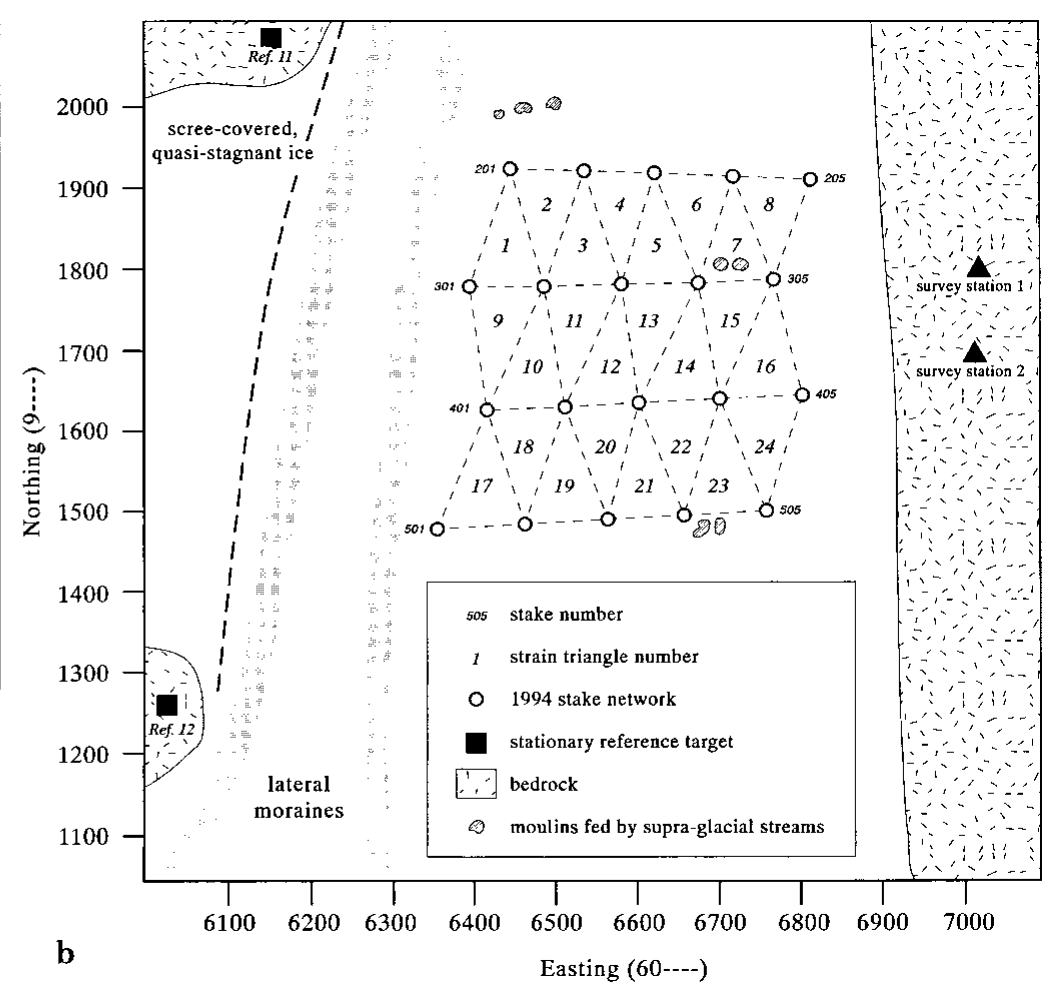

Easting (60----)

Fig. 1. Location of Haut Glacier d'Arolla with close-up of stake network, survey stations and reference targets. 

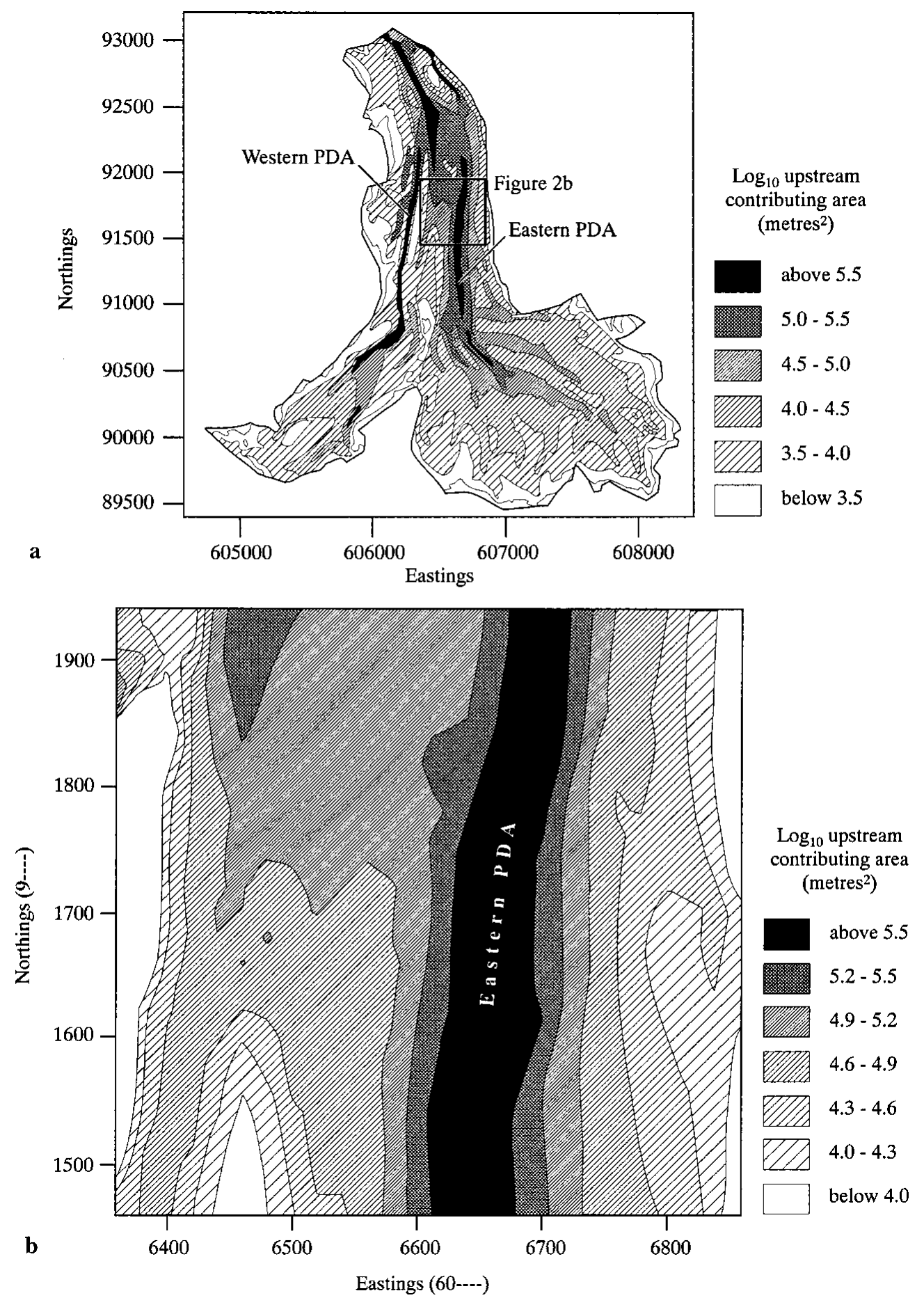

Fig. 2. Map of the up-glacier contributing area on the hydraulic potential surface, illustrating the means of identifying the likely subglacial drainage configuration. The digital elevation model is based on a $20 \mathrm{~m}$ grid, and the key defines classes of the common logarithm of contributing area. Darker areas indicate PDAs (based on Sharp and others, 1993).

and others, 1998). As the snowline retreats up-glacier it continually exposes new moulins and crevasses and subjects them to diurnally peaked inputs of ice-derived meltwater. On a glacier-wide scale, therefore, channel growth occurs in an $u p$ glacier direction along the PDAs at the expense of the distributed system. Locally, however, channel growth is probably directed down-glacier from individual moulins (Gordon and others, 1998; Nienow, and others, 1998). It is also likely that high discharges associated with early-season rainstorms contribute to subglacial channel formation (Gordon and others, 1998; Nienow and others, 1998). Large areas of distributed drainage persist between PDAs even after channelization has occurred (Hubbard and others, 1995; Nienow and others, 1998). Subglacial channels are characterized by high-ampli- tude diurnal water-pressure fluctuations in response to large diurnal variations in water discharge (Hubbard and others, 1995; Gordon and others, 1998). The distributed drainage system is characterized by generally higher, less variable water pressures. Hubbard and others (1995) showed that during high water discharges, channel water pressures are higher than water pressures in the adjacent distributed drainage system. The pressure gradient therefore forces water laterally out from the channel, into the adjacent distributed system. As discharge drops, channel water pressures fall below the pressures in the distributed drainage system, and water is driven back towards the channel. Lateral water flows at the glacier bed involve the temporary storage of waters in the distributed system over diurnal time-scales 
(Hubbard and others, 1995). Gordon and others (1998) showed anticorrelation amongst oscillating subglacial water-pressure signals from boreholes located within the region of channelized drainage. This suggests that as water pressure in the channel approaches ice overburden pressure, localized bed separation occurs around the channel. This creates voids, allowing water to drain more rapidly from these areas and causing water pressures to fall. When the high water-pressure wave, propagated from the channel, reaches these adjacent areas, drainage is impeded and water pressures within them rise again.

\section{MEASUREMENT AND ANALYSIS OF GLACIER ICE DYNAMICS}

\section{Surface motion}

Glacier surface motion was recorded across part of the glacier tongue centred on a borehole array, about $1500 \mathrm{~m}$ from the glacier snout. Ice thicknesses in the study area range from about $40 \mathrm{~m}$ near the margins to about $130 \mathrm{~m}$ in the glacier centre. Surface motion was determined from repeat surveys of prisms mounted on stakes drilled into the glacier. In early June 1994, a network of 20 motion stakes was established. Rows of stakes were staggered to create a network of surface strain triangles (Fig. 1). Two survey stations, approximately $100 \mathrm{~m}$ apart, were established on bedrock outcrops on the eastern valley side (Fig. 1). Surveys were carried out using a Geodimeter 410 total station system with an accuracy in distance measurement of $\pm(2 \mathrm{~mm}+3 \mathrm{ppm})$. This equates to a range of error values of $2.5-4 \mathrm{~mm}$ over the range of distances surveyed. Horizontal and vertical angles from survey station to stake were measured to within $2^{\prime \prime}$ of arc. This contributes errors of 2-6 mm to stake coordinate positions over the range of distances surveyed. Two reference targets, with reflective prisms attached, were fixed to bedrock outcrops on the western valley side (Fig. 1). Repeat surveys to these references allowed for determination of, and compensation for, errors associated with setting up the Geodimeter upon each survey tripod, and with changes in temperature or pressure during each survey. Details of error calculations are given in Appendix I.

\section{Surface strain rates}

Surface strain rates were calculated from the deformation of strain triangles formed by the staggered rows of motion stakes (Fig. 1). For each strain triangle, we calculated the position of the centre of the strain triangle, the two perpendicular principal strains $\left(\varepsilon_{1,2}\right)$ and the angle of orientation of the first principal strain relative to north $(\theta)$. Strain rate was assumed to be homogeneous within the strain triangles. Ramsay (1967) describes in full the method by which the magnitude and direction of the principal strains were calculated. Longitudinal strain $\left(\varepsilon_{x x}\right)$, transverse strain $\left(\varepsilon_{y y}\right)$ and shear strain $\left(\varepsilon_{x y}\right)$ were calculated, where $x$ is the flow direction, which is north, and $y$ is cross-flow direction increasing to the east. Vertical strain $\left(\varepsilon_{z z}\right)$ was calculated, assuming incompressibility of ice (the vertical dimension, $z$, is measured in ma.s.l.). Strain rates were obtained by dividing the strains by the time period between surveys.

\section{Force-budget analysis}

The area of the glacier covered by the strain triangle network was divided into an array of 12 overlapping "blocks" (Fig. 3). Horizontal dimensions of each block were about $0.8-1.5$ block thicknesses (block thicknesses were taken as the mean ice thickness across the horizontal area of each block). Ice thicknesses were calculated from the map of bed topography derived from radar measurements carried out by Sharp and others (1993; Fig. 1) and from surface elevations measured at each stake position. Stress was calculated from measured surface strain rate and multiplied by the respective area of each side of each block to estimate the longitudinal forces on the up- and down-glacier ends of the blocks and shear forces on their sides. Subtracting the driving force for each block leaves the resistive basal drag as a residual. The full force-budget equations are given in Appendix II.

This approach is the plug- or block-flow approach used by Whillans and others (1989) along Byrd Station Strain Network, Antarctica, by Hooke and others (1989) at Storglaciären, by Van der Veen and Whillans (1993) at Columbia Glacier, and by Iken and Truffer (1997) at Findelengletscher, Switzerland. In this model there is no downward stepping involved, contrary to the full force-budget technique derived by Van der Veen and Whillans (1989) which starts at the surface and calculates velocities and stresses at depth. By its simplicity it avoids the problems with mathematical or numerical instabilities often encountered in inverse calculations (Blatter, 1995).

The model assumes depth-independent strain rates. This is a significant limitation to the application of this model over small horizontal scales, i.e. of the order of ice thickness. Balise and Raymond's (1985) viscous linear flow model sug-

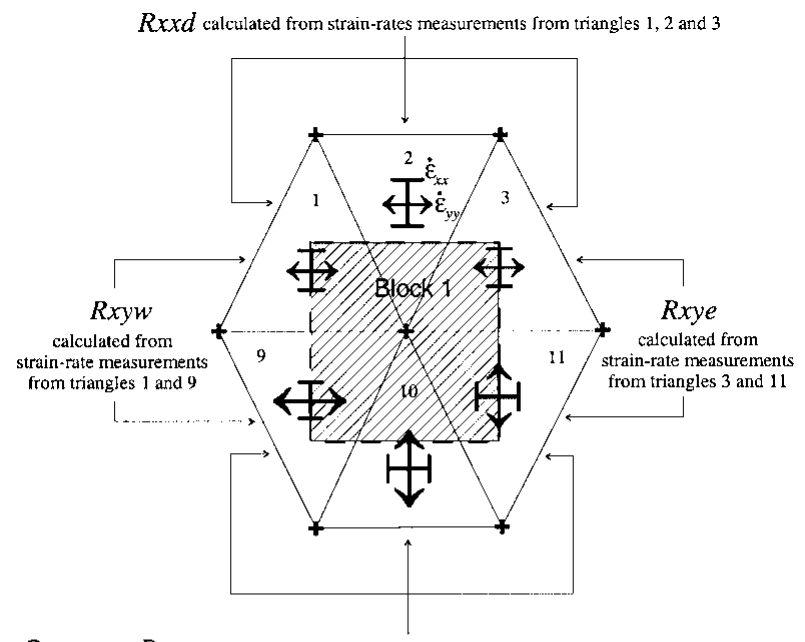
$R x x u$ calculated from strain-ratc measurements from triangles 9,10 and 11

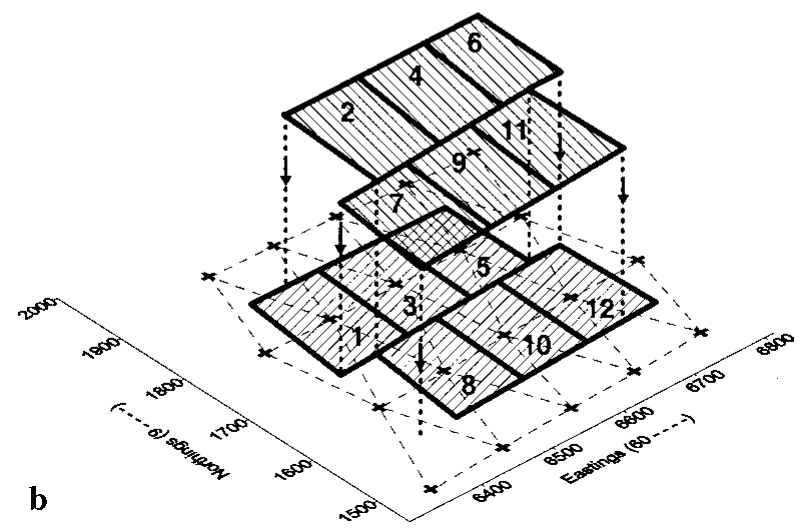

Fig. 3. (a) Illustration of how strain-rate measurements are combined to calculate the different resistive forces acting on a force-budget block (e.g. block 1). (b) Layout of the 12 overlapping force-budget blocks within the stake network. 
gested that at length scales of less than about five ice thicknesses, strain rates do vary with depth and that complex variations in stress can cause surface motion to appear quite different to that at depth. They, and others (e.g. Blatter, 1995; Lliboutry, 1995), have therefore suggested that force-budget models which make this assumption may be of limited use. However, to determine whether spatial variations in basal drag are controlled by subglacial hydrology, it is essential to apply the force-budget method across the horizontal scale at which spatial variations in subglacial drainage conditions can be identified. This is of the order of one ice thickness at Haut Glacier d'Arolla (Hubbard and others, 1995; Gordon and others, 1998). Force-budget blocks of this scale were therefore used in our analysis. Recognizing the method's limitations over blocks of this scale, and to avoid overinterpretation of the data, spatial variations in basal drag were considered significant only when the pattern of variation was consistent over several adjacent blocks. To ensure that calculated spatial patterns of basal drag are not purely an artefact of the scale and spacing of the force-budget blocks, the force-budget analysis across the entire study area was repeated for four larger blocks, each with a length scale of 2-3 ice thicknesses. The spatial pattern of basal drag calculated from the smaller blocks was only considered significant if consistent with the pattern across the larger blocks. In addition, no significance is attached to the absolute values of the resistive forces determined, since these depend very much on the values of the flow-law parameters used in the calculations. In the light of the above caveats, it is expected that this method will provide an indicator of spatial and temporal changes in basal drag across the glacier tongue.

\section{RESULTS}

\section{Temporal variation in surface velocity, 1994 melt season}

Daily and 5 day average glacier surface velocities in the direction of glacier flow $\left(v_{x}\right)$ at three stakes during the 1994 melt season are shown in Figure 4. The main feature of these records is a major increase in velocity at all stakes between Julian day (JD) 173 and JD179 (22 and 28 June) which we term a "spring event". Increased surface motion coincided with a period of rapidly rising discharge in the proglacial stream, $Q_{\mathrm{w}}$, between JD173 and JD178 (Fig. 5a), which was a consequence of high air temperatures (particularly overnight), T, and sustained rainfall, Ppt (Fig. 5b and c). These coincided with a strong föhn wind and created the first large increase in water inputs to the glacier during the 1994 melt season. After about JD180, surface velocity was not well correlated with $Q_{\mathrm{w}}$ or $T$. Although motion increased across the whole glacier tongue during the spring event, there were large variations in the degree to which velocity changed along both transverse and longitudinal profiles.

\section{Observed features of spatial patterns of glacier motion}

Spatial patterns of glacier surface velocity, strain rates and force-budget components were calculated for multi-day periods immediately preceding (JD169-173), during (JD173-179) and after (JD179-185) the 1994 spring event (Figs 6-8). The time periods chosen are the longest into which the motion data can be divided while still defining hydrologically distinct periods. Errors associated with strainrate and force-budget results are quite large (Appendix II, Tables 3 and 4). They would be reduced if calculations were performed for longer periods, but it would then be impossible to investigate the changes in strain-rate fields and force budget that occurred during the motion event. The main features of the spatial patterns of glacier motion for these three periods are now summarized.

Before the spring event ( $7 D 169-173)$

(a) Low surface velocity across the entire study area (Fig. 6a);

(b) generally higher surface velocity east of the glacier centre line (i.e. east of approximately $606600 \mathrm{E}$ ) than towards the west (Fig. 6a);

(c) lowest velocity towards the western margin and extending towards the glacier centre, creating a band of longitudinal compression across the study area (Fig. 7a);

(d) steady downwards surface displacement across the entire study area (Fig. 9);

(e) high basal drag below the down-glacier blocks (centred around $91800 \mathrm{~N}$ ), associated with the fact that ice flow in this area was driven by the push (and pull) from slightly faster-moving ice up- (and down-) glacier as well as by the local driving stress (Figs 8a and 6a).

During the spring event (7D173-179)

(a) High, but temporally and spatially variable, surface longitudinal velocity across most of the study area, with higher velocity predominantly to the east of the glacier centre (Fig. 6b);

(b) surface uplift of the glacier during the period of glacier acceleration from JD173 to JD175, initiating in the region to the east of the glacier centre (where surface longitudinal velocity was greatest) and propagating downglacier and west across the entire study area (Fig. 9);

(c) widespread surface lowering during the period of glacier deceleration from JD175 toJD179 (Fig. 9);

(d) a pattern of longitudinal extension up-glacier turning to longitudinal compression down-glacier across the eastern half of the study area (Fig. 7b);

(e) the removal of all areas of very high basal drag (Fig. 8b);

(f) lowest basal drag below the most easterly force budget blocks and below the most westerly, down-glacier block (Fig. 8b).

After the spring event ( FD179-185)

(a) The complete disappearance of areas of fast-flowing ice (Fig. 6c);

(b) the establishment of an area of very low horizontal motion in the upper eastern area where surface velocity was highest during the spring event (Fig. 6c);

(c) a very rapid surface lowering of the glacier in this upper eastern area of very low horizontal motion immediately after the spring event terminated between JD179 and JD180 (Fig. 9; cf. Fig. 4a);

(d) the establishment of very high basal drag in the upper eastern area of low horizontal motion and rapid downwards displacement (Fig. 8c); 


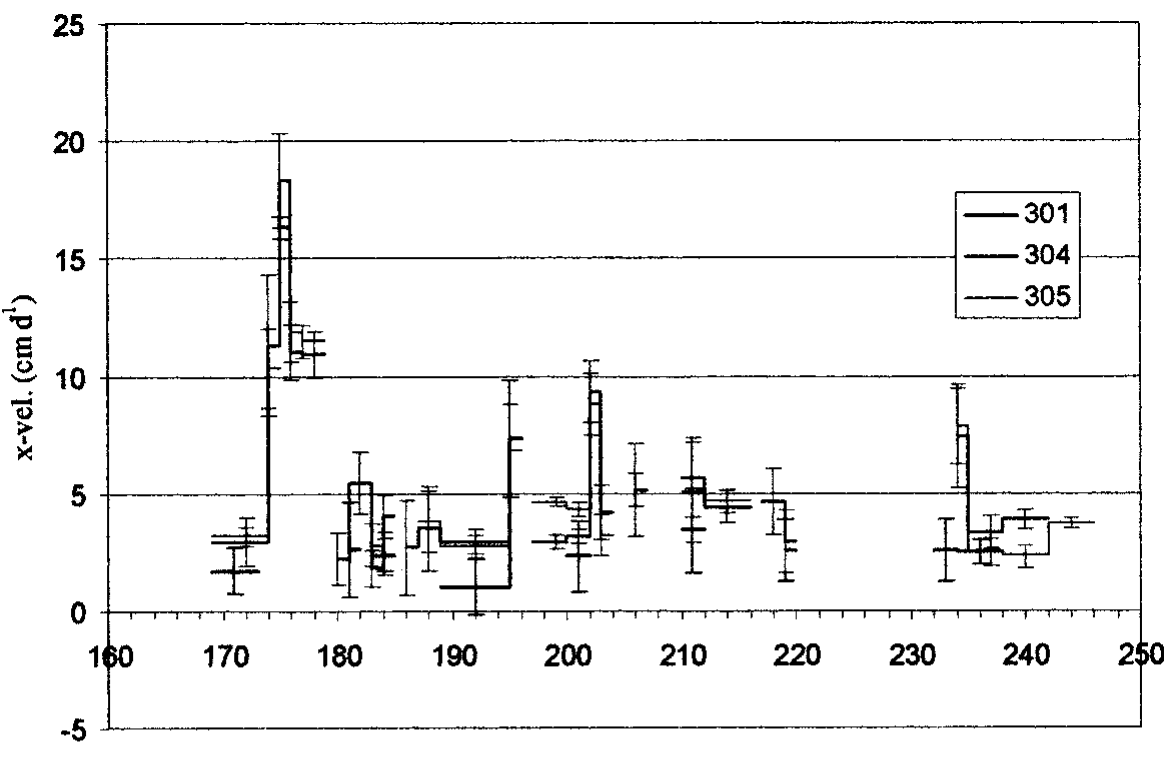

a

Julian day

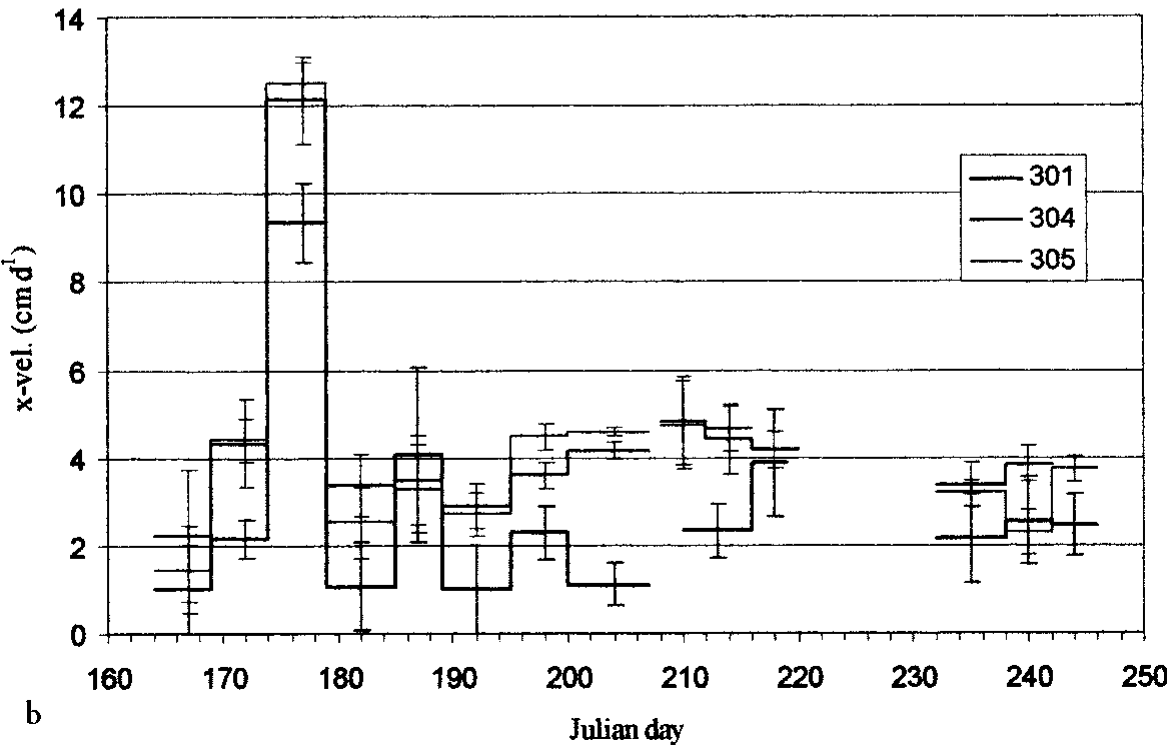

Fig. 4. Temporal record of longitudinal velocities, $v_{x}$, throughout the 1994 melt season. (a) Although referred to as "daily" velocities, some of the measurements are averages over longer periods because surveys could not be undertaken during bad weather. The gaps in the velocity records resulted when stakes could not be resurveyed after they had been redrilled, or if measurement errors were very high. (b) Temporal variations in velocity were averaged over time intervals of approximately 5 days, here referred to as " 5 day" velocities. This reduces errors and allows for a more continuous velocity record.

(e) more gradual surface lowering after the spring event across areas further to the west and down-glacier (Fig. 9);

(f) the persistence of low basal drag across the rest of the stake network where surface lowering is more gradual (Fig. 8c).

\section{INTERPRETATION OF SPATIAL PATTERNS}

Although subglacial hydrological conditions were not measured during the 1994 spring event, PDAs tend to form in approximately the same location each year (Gordon, 1996) and evolve each summer from distributed to channelized drainage axes as the snowline migrates up-glacier. These same conditions are therefore also likely to have applied during the 1994 melt season.

Within the study area there appears to be an association between patterns of motion and the configuration of the subglacial drainage system (cf. Fig. 2 and Figs 6-9). The eastern PDA is fed by moulins located just up-glacier of the stake network (cf. Fig. 1 and Fig. 2). The area of the eastern PDA immediately down-glacier from these moulins is characterized by the largest changes in longitudinal velocity, vertical velocity, longitudinal strain rates and basal drag. The horizontal scale of the basal-drag changes in this area is of the same order as the ice thickness and so may be subject to the limitations in interpretation discussed earlier. However, the values of the magnitude of the ratio of basal drag to driving stress (BD/DS) across the four larger force-budget blocks describe essentially the same temporal and spatial pattern as observed over the smaller blocks (cf. Table 1 and Fig. 8). This result increases our confidence in the spatial pattern of basal drag as calculated across the smaller blocks.

These observations suggest that the spatial configuration of the subglacial drainage system may have had a strong influence on the spatial and temporal patterns of glacier motion during and immediately after the spring event. On the basis of these observations the evolution and termination of the spring event is interpreted as follows.

The spring event occurred at a time when the entire glacier 

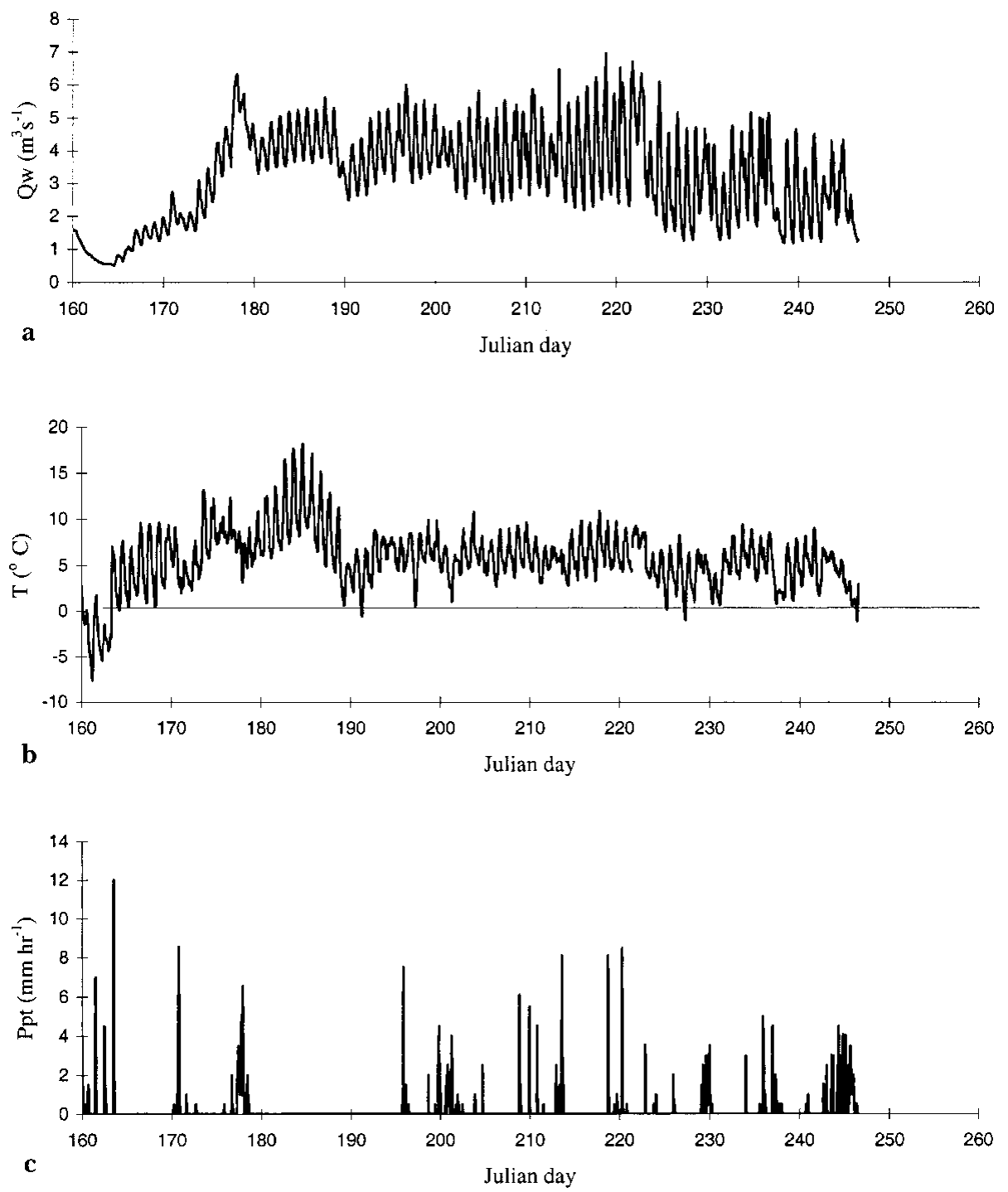

Fig. 5. (a) Proglacial stream discharge, $Q_{\mathrm{w}}$, 1994. (b) Air temperature, T, 1994. (c) Precipitation, Ppt, 1994.

was snow-covered. Beyond $700 \mathrm{~m}$ up-glacier from the glacier snout, conduits formed during the previous melt season will close by ice deformation during the winter (Nienow and others, 1998). The entire study area would therefore be underlain by a distributed subglacial drainage system at the start of each melt season (Richards and others, 1996; Nienow and others, 1998). A combination of high air temperature (particularly overnight) followed by very high rainfall caused high rates of snowmelt input to the subglacial drainage system via moulins and crevasses. Theory suggests that increased discharge through a distributed drainage system causes increased subglacial water pressures (Walder, 1986; Kamb, 1987). Therefore, the spring event most likely involved increased rates of basal motion promoted by high subglacial water pressures. The area of the eastern PDA

Table 1. Four-block force budget ( $B D / D S$ ). Blocks 1-4 represent the following sectors of the study area, respectively: downglacier western, down-glacier eastern, up-glacier western and up-glacier eastern

\begin{tabular}{lllll}
\hline & Block 1 & Block 2 & Block 3 & Block 4 \\
\hline JD169-173 & 1.66 & 1.43 & 0.7 & 0.4 \\
JD173-179 & 0.45 & 0.8 & 1.14 & 0.61 \\
JD179-185 & 0.52 & 0.83 & 0.81 & 1.93 \\
\hline
\end{tabular}

immediately down-glacier from the set of moulins at approximately $606680 \mathrm{E}, 91450 \mathrm{~N}$ (Fig. 1) is likely to have received the greatest increase in meltwater inputs within the study area. A rapid increase in subglacial water pressures in this area may have led to bed separation. A detailed analysis of vertical motion during the spring event (D. Mair and others, unpublished information) suggests that vertical strain cannot account for the observed surface uplift. Propagation of surface uplift from this upper eastern area to the rest of the study area may be evidence of propagation of bed separation. Widespread bed separation is likely to have been responsible for removing localized areas of high basal drag during the spring event. Surface velocity patterns suggest that basal motion was probably greatest along the eastern PDA. Peak horizontal velocity and highest surface uplift were attained about 3 days before peak discharge in the proglacial stream (i.e. on JD175 as opposed toJD178).

Although the subglacial drainage system remained pressurized throughout the spring event, it may have become more hydraulically efficient over the last 3 days of the event so that higher meltwater discharges were accommodated at slightly lower pressures. This may have occurred as bed separation (due to high subglacial water pressures) and frictional melting of basal ice (due to high water discharges) combined to enlarge water-filled cavities between the bed and the glacier. Such a process may have been the first stage of incipient subglacial channel development. In addition, 


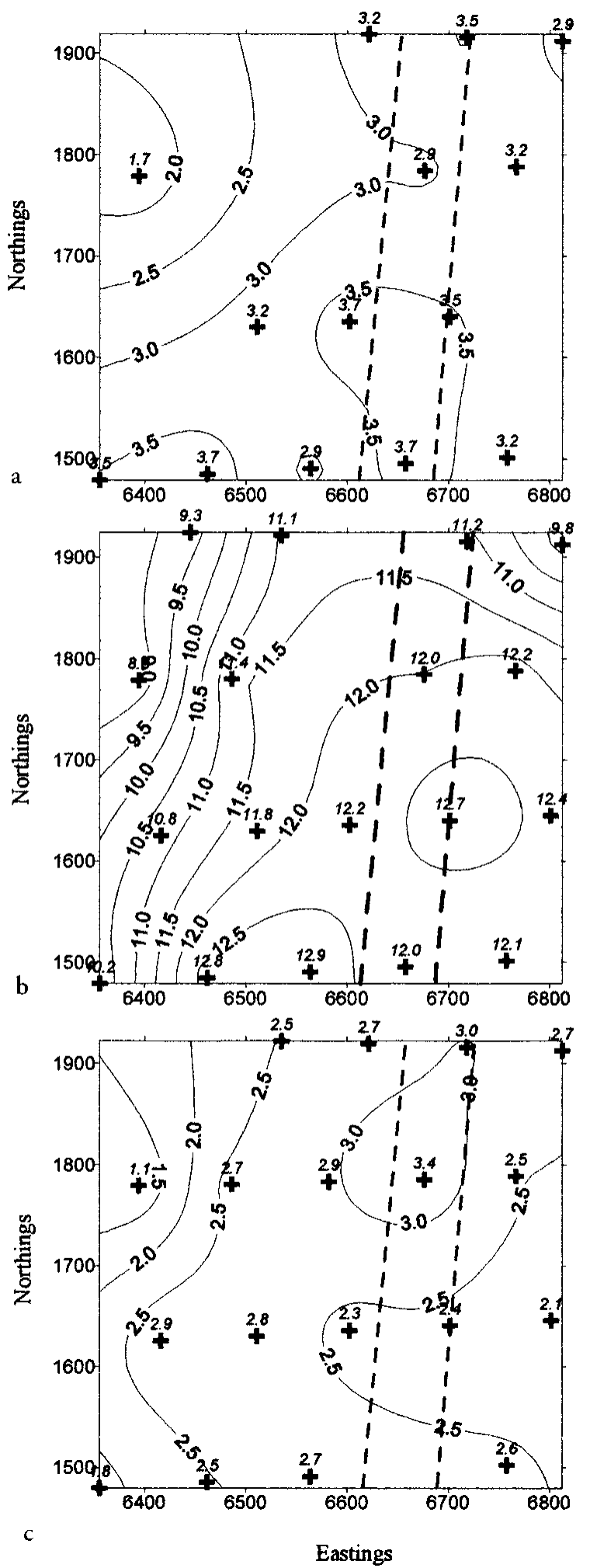

Fig. 6. Surface longitudinal velocities ( $\left.\mathrm{cm} \mathrm{d}^{-1}\right)$. (a) $7 D 169$ 173; ( b ) 7D173-179; (c) 7D179-185. Location of eastern PDA marked.

the propagation of the zone of bed separation beyond the study area may have allowed water originally stored within the study area to drain to newly separated areas further down-glacier, thus allowing water pressure within the study area to decrease.

At the end of the spring event both air temperature and rainfall dropped. This is likely to have caused a rapid reduction in water inputs to the subglacial drainage system, causing water pressures to drop rapidly. The most rapid drop in surface longitudinal velocity and most rapid surface lowering were recorded in the upper eastern area where surface

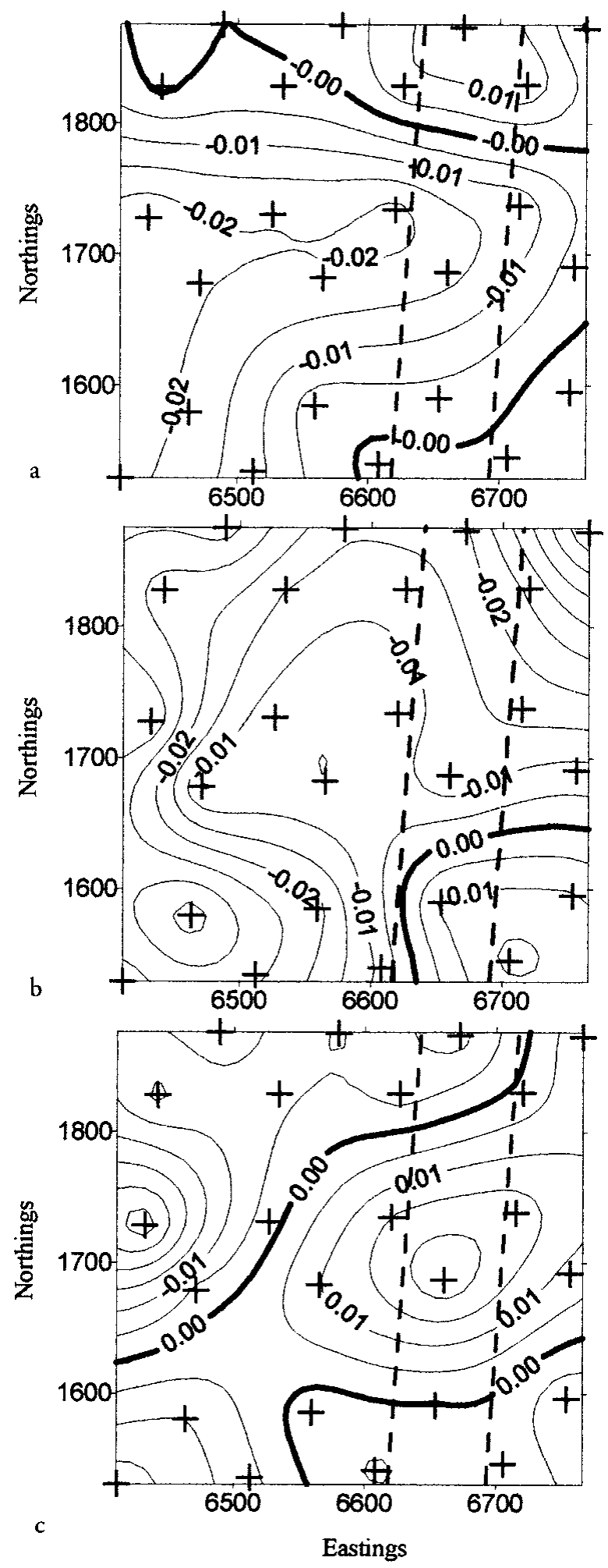

Fig. 7. Surface longitudinal strain rates $\left(a^{-1}\right)$. Crosses mark centre points of each strain triangle. (a) FD169-173; (b) 7D173-179; (c) 7D179-185. Location of eastern PDA marked.

velocity and surface uplift were greatest during the event. This suggests that subglacial water pressure fell most rapidly in this area, indicating that stored water was able to drain away most rapidly along the eastern PDA. This is most likely to have occurred if the enlargement of basal cavities during the event was greatest along the eastern PDA, particularly in the area immediately down-glacier from the moulins. The creation of very high basal drag in this area immediately after the event may be a direct consequence of such a rapid drop in water pressure.

Across the rest of the glacier tongue, the reduction in sur- 


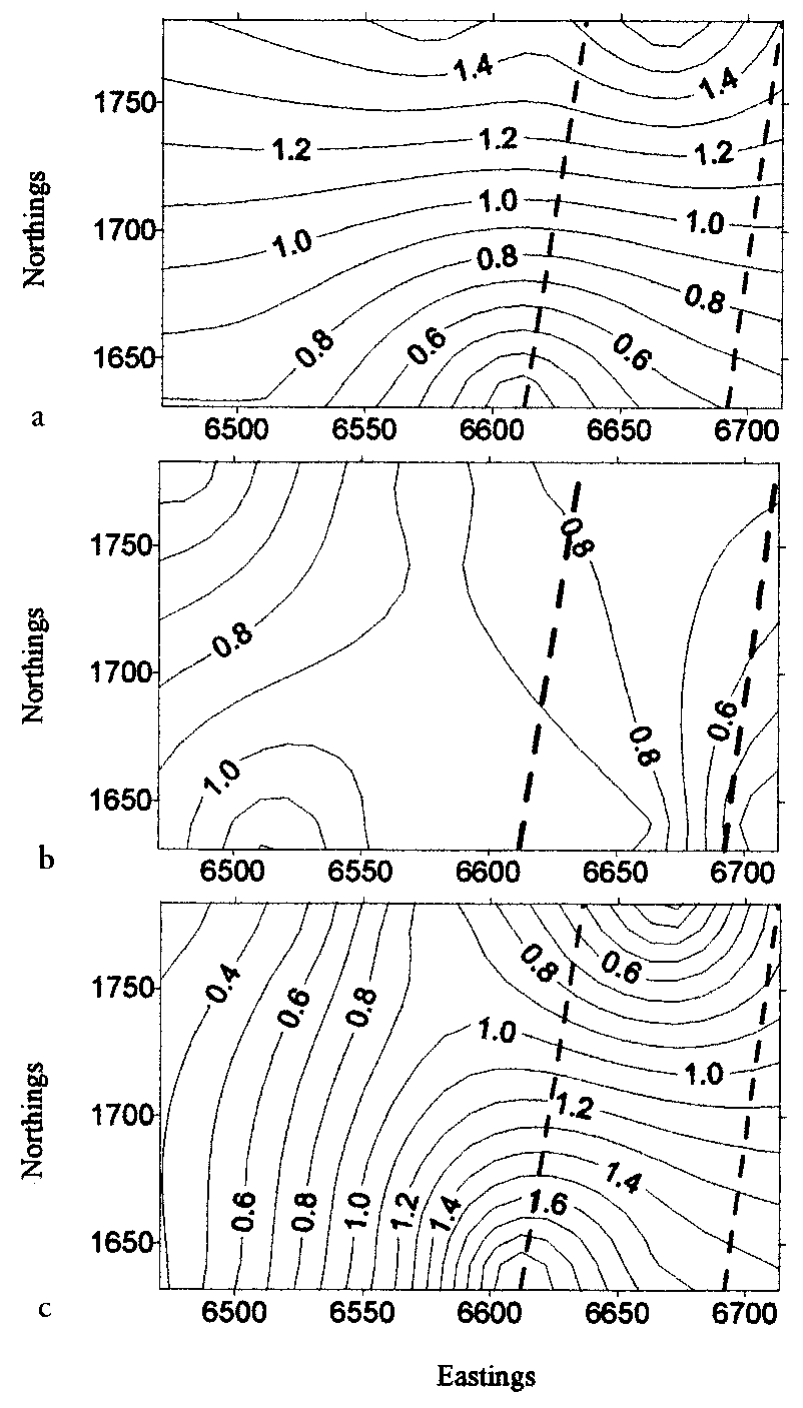

Fig. 8. Spatial representation of BD/DS. The spatial pattern of contours is constructed by interpolating between the values of $B D / D S$ for each block, which although representing an areal average are assigned to points at the centre of each block. Since the blocks overlap, the resulting plot is a highly abstracted representation of spatial variation in basal drag across the stake network. Areas where $B D / D S>1$ indicate flow is driven, in part, by forces other than the driving force. Areas where $B D / D S<1$ indicate that resistance to glacier flow comes, in part, from sources which are non-local. (a) 7D169-173; (b) 7D173179; ( c) 7D179-185. Location of eastern PDA marked.

face horizontal motion and surface lowering after the spring event were more gradual, and low basal drag persisted for longer. This suggests that the reduction in subglacial water pressures in these areas was less rapid. This is consistent with the suggestion made above that rates of cavity enlargement during the event may have been lower in these areas than along the eastern PDA. The subglacial drainage system in these areas may have remained more hydraulically inefficient than along the eastern PDA. Water would have been stored in the drainage system for longer, and would have taken longer to drain away. Thus, lowering of the glacier back onto its bed was more gradual. During this period, areas of low drag did not lead to localized areas of high surface velocities since glacier motion was restrained by high longitudinal resistive forces (cf. Figs 8c and 7c). The implications of this result are discussed further in the following section.

Thus, the termination of the spring event may have been due to (1) a reduction in water input to the subglacial drain- age system (external mechanism), and/or (2) a restructuring of the subglacial drainage system (internal mechanism). The lack of correlation between surface velocity and $Q_{\mathrm{w}}$ immediately after the spring event when air temperatures were especially high (JD180-185) may indicate that renewed high discharges did not lead to widespread areas of high subglacial water pressure. This would be expected if the drainage system had become more hydraulically efficient after the spring event as a result of cavity enlargement during the spring event. Thus internal mechanisms may be more important than external ones in causing spring-event termination. Direct measurement of subglacial water pressures and detailed measurements of surface motion throughout a spring event are required to resolve this issue.

\section{DISGUSSION}

The spatial patterns of basal drag during and after the spring event strongly suggest that variations in subglacial hydrology along the eastern PDA can create areas of low and high basal drag. A localized, hydrologically induced reduction (increase) in basal drag increases (reduces) it in surrounding areas. Force-budget considerations mean that areas of high drag must have been located outside of the study area during the spring event. The results presented here are therefore consistent with the conclusions of Fischer and others (1999), who suggested that a glacier bed may be considered as a spatially and temporally variable array of sticky and slippery spots which can be created and destroyed by changes in subglacial hydrology.

The relationship between changes in patterns of basal drag and glacier motion is not straightforward. There is no clear local relationship between basal drag and glacier motion at the horizontal scale of about one ice thickness (the scale of an individual force-budget block) because of coupling to surrounding areas. This result is consistent with the conclusions of theoretical studies (Balise and Raymond, 1985; Kamb and Echelmeyer, 1986). The large acceleration in glacier motion that occurred across the entire study area was due to both the creation of an area of unusually low basal drag and the removal of areas of high basal drag in surrounding areas. As mentioned above, areas of high drag would still have existed, but these must have been located in areas far enough away from the study area that their restraining influence on glacier motion in the study area was low and could not prevent widespread glacier acceleration. This suggests that enhanced glacier motion across the study area was dependent upon a change in the spatial distribution of areas of high drag across the glacier. Considering the horizontal scale of the study area, it appears that sticky spots must be removed from areas of the bed with length scales of the order of at least four ice thicknesses before a high-velocity event can occur.

\section{GONGLUSIONS}

Despite important limitations, inverse force-budget analysis has been applied with some success to identify spatial and temporal changes in basal forcing beneath the tongue of a temperate valley glacier. During a spring high-velocity event, areas of low basal drag corresponded with areas of (1) highest surface velocity, (2) highest surface uplift and (3) preferred subglacial drainage. After the spring event, the area of high- 


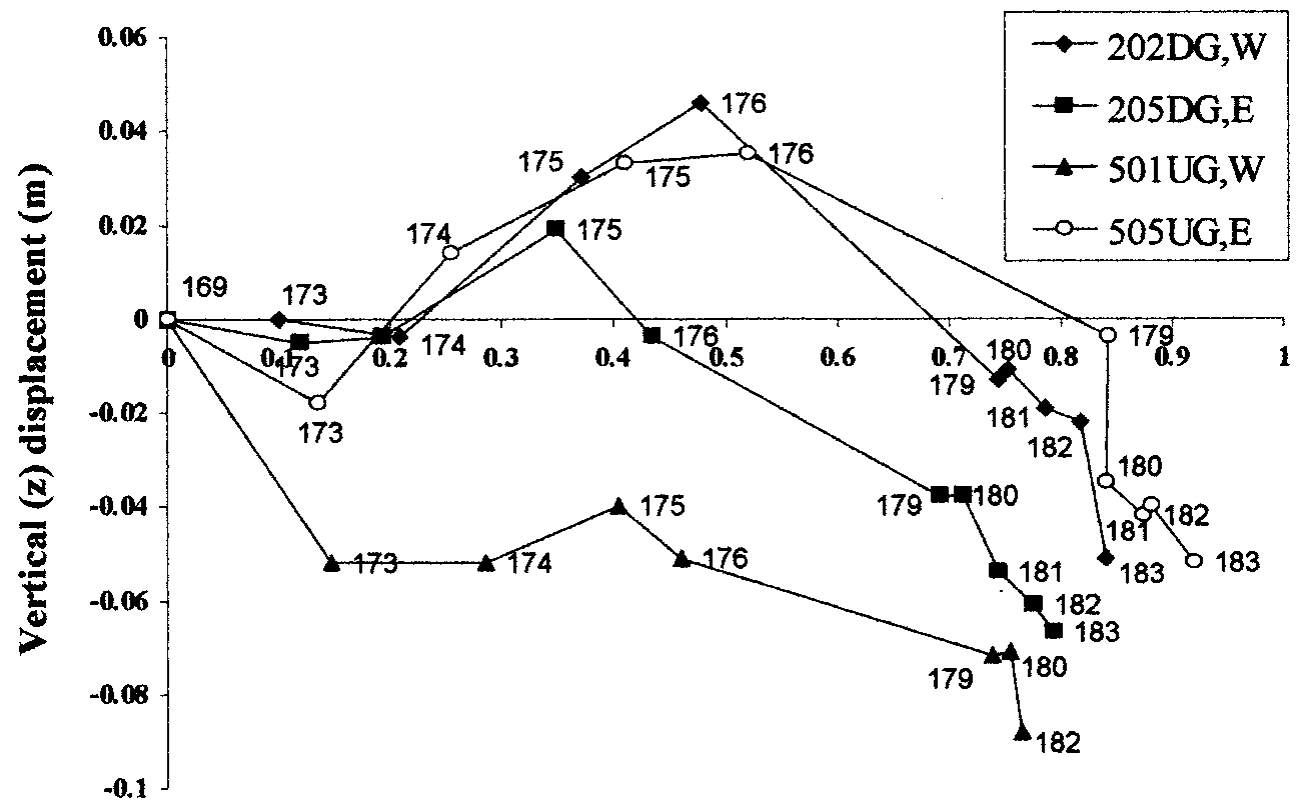

Longitudinal (x) displacement (m)

Fig. 9. Displacement of selected motion stakes in the xz-plane before, during and after the 1994 spring event. Abbreviations relate to approximate stake positions ( DG, down-glacier; $U G$, up-glacier; $W$, west; E, east). Points are labelled according to $\mathcal{J}$ ulian day of survey. (a) Stake 202 (DG,W); (b) stake 205 (DG,E); (c) stake 501 (UG,W); (d) stake 505 (UG,E). Displacements are relative to position on $7 D 169$, except stake 202 which begins with zero vertical displacement on $7 D 173$.

est basal drag corresponded with an area of (1) anomalously low surface velocities and (2) high surface lowering. No clear relationship between basal drag and glacier motion is apparent over length scales of about one ice thickness. Results suggest that a spring event can occur only when changes in subglacial hydrology can remove sticky spots from areas with length scales of the order of four ice thicknesses.

The results of this study highlight the importance of determining spatial as well as temporal variations in subglacial hydrology and glacier motion in order to better understand the relationship between the two. The ideas presented are qualitatively similar to those discussed by other authors (Balise and Raymond, 1985; Iken and Truffer, 1997; Fischer and others, 1999). Local variations in glacier motion cannot simply be explained as a response to local variations in subglacial hydrology. Attempts to derive glacier flow models which assume that glacier motion at a point is a function of locally defined variables are of limited use in understanding the relationships between basal conditions and glacier motion. Only by a close combination of fieldwork and modelling can progress be made towards understanding what controls patterns of basal drag beneath glaciers and how this influences three-dimensional patterns of stress and velocity fields via longitudinal and transverse coupling.

\section{AGKNOWLEDGEMENTS}

Our work was supported by Natural Environment Research Council (NERG) Studentship GT4/93/6/P (Mair), NERG Fellowship GT3/93/AAPS/1 (Nienow) and NERG Grant GR3/8114. Field assistance was provided by M. Nielsen and B. Hubbard. Grande Dixence SA, Y. Bams, V. Anzevui and P. and B. Bournissen provided logistical support. The comments of C.F. Raymond and two anonymous referees helped to improve this paper.

\section{REFERENGES}

Arnold, N., K. Richards, I. Willis and M. Sharp. 1998. Initial results from a distributed, physically based model of glacier hydrology. Hydrol. Processes, $12(2), 191-219$.

Balise, M. J. and C. F. Raymond. 1985. Transfer of basal sliding variations to the surface of a linearly viscous glacier. f. Glaciol., 31 (109), 308-318.

Blatter, H. 1995. Velocity and stress fields in grounded glaciers: a simple algorithm for including deviatoric stress gradients. F. Glaciol., 41(138), 333-344.

Fischer, U. H, G. K. C. Clarke and H. Blatter. 1999. Evidence for temporally varying "sticky spots" at the base of Trapridge Glacier, Yukon Territory, Canada. F. Glaciol., 45(150), 352-360.

Fountain, A. G. 1993. Geometry and flow conditions of subglacial water at South Cascade Glacier, Washington State, U.S.A.; an analysis of tracer injections. F. Glaciol., 39(131), 143-156.

Fountain, A. G. 1994. Borehole water-level variations and implications for the subglacial hydraulics of South Cascade Glacier, Washington State, U.S.A. F. Glaciol., 40(135), 293-304.

Glen, J.W. 1955. The creep of polycrystalline ice. Proc. R. Soc. London, Ser. A, 228(1175), 519-538.

Gordon, S. 1996. Borehole based investigations of subglacial hydrology. (M.Sc. thesis, University of Alberta.)

Gordon, S., M. Sharp, B. Hubbard, C. Smart, B. Ketterling and I. Willis. 1998. Seasonal reorganization of subglacial drainage inferred from measurements in boreholes. Hydrol. Processes, 12, 105-133.

Harbor, J., M. Sharp, L. Copland, B. Hubbard, P. Nienow and D. Mair. 1997. The influence of subglacial drainage conditions on the velocity distribution within a glacier cross section. Geology, 25(8), 739-742.

Hooke, R. LeB., P. Calla, P. Holmlund, M. Nilsson and A. Stroeven. 1989. A 3 year record of seasonal variations in surface velocity, Storglaciären, Sweden. 7. Glaciol., 35(120), 235-247.

Hubbard, A., H. Blatter, P. Nienow, D. Mair and B. Hubbard. 1998. Comparison of a three-dimensional model for glacier flow with field data from Haut Glacier d'Arolla, Switzerland. F. Glaciol., 44(147), 368-378.

Hubbard, B. P., M. J. Sharp, I. C. Willis, M. K. Nielsen and C. C. Smart. 1995. Borehole water-level variations and the structure of the subglacial hydrological system of Haut Glacier d'Arolla, Valais, Switzerland. $\mathcal{F}$. Glaciol., 41 (139), 572-583.

Iken, A. and R. A. Bindschadler. 1986. Combined measurements of subglacial water pressure and surface velocity of Findelengletscher, Switzerland: conclusions about drainage system and sliding mechanism. F. Glaciol., 32(110), 101-119.

Iken, A. and M. Truffer. 1997. The relationship between subglacial water pressure and velocity of Findelengletscher, Switzerland, during its advance and retreat. F. Glaciol., 43(144), 328-338.

Iken, A., H. Röthlisberger, A. Flotron and W. Haeberli. 1983. The uplift of 
Unteraargletscher at the beginning of the melt season - a consequence of water storage at the bed? F. Glaciol., 29(101), 28-47.

Iverson, N. R., B. Hanson, R. LeB. Hooke and P. Jansson. 1995. Flow mechanism of glaciers on soft beds. Science, 267(5194), 80-81.

Jansson, P. 1995. Water pressure and basal sliding on Storglaciären, northern Sweden. f. Glaciol., 41 (138), 232-240.

Kamb, B. 1987. Glacier surge mechanism based on linked cavity configuration of the basal water conduit system. F. Geophys. Res., 92(B9), 9083-9100.

Kamb, B. and K. A. Echelmeyer. 1986. Stress-gradient coupling in glacier flow: I. Longitudinal averaging of the influence of ice thickness and surface slope. 7. Glaciol., 32(111), 267-284.

Kamb, B. and H. Engelhardt. 1987. Waves of accelerated motion in a glacier approaching surge: the mini-surges of Variegated Glacier, Alaska, U.S.A. f. Glaciol., 33(113), 27-46.

Lliboutry, L. 1995. Correspondence. Why calculated basal drags of ice streams can be fallacious. 7. Glaciol., 41(137), 204-205.

Murray, T. and G. K. C. Clarke. 1995. Black-box modeling of the subglacial water system. F. Geophys. Res., 100 (B7), 10,231-10,245.

Nienow, P., M. Sharp and I. Willis. 1998. Seasonal changes in the morphology of the subglacial drainage system, Haut Glacier d'Arolla, Switzerland. Earth Surf. Processes Landforms, 23, 825-843.

Nye, J. F. 1957. The distribution of stress and velocity in glaciers and icesheets. Proc. R. Soc. London, Ser. A, 239(1216), 113-133.

Ramsay, J. G. 1967. The folding and fracturing of rocks. New York, McGraw-Hill.

Richards, K. S. and 9 others. 1996. An integrated approach to modelling hydrology and water quality in glacierized catchments. Hydrol. Processes, 10(4), 479-508.

Sharp, M. and 6 others. 1993. Geometry, bed topography and drainage system structure of the Haut Glacier d'Arolla, Switzerland. Earth Surf. Processes Landforms, 18(6), 557-571.

Van der Veen, C. J. and I. M. Whillans. 1989. Force budget: I. Theory and numerical methods. f. Glaciol., 35(119), 53-60.

Van der Veen, C. J. and I. M. Whillans. 1993. Location of mechanical controls on Columbia Glacier, Alaska, U.S.A., prior to its rapid retreat. Arct. Alp. Res., 25(2), 99-105.

Walder, J. S. 1986. Hydraulics of subglacial cavities. F. Glaciol., 32(112), 439-445 Weertman, J. 1964. The theory of glacier sliding. F. Glaciol., 5(39), 287-303.

Whillans, I. M., Y. H. Chen, C. J. van der Veen and T. J. Hughes. 1989. Force budget: III. Application to three-dimensional flow of Byrd Glacier, Antarctica. 7. Glaciol., 35(119), 68-80.

\section{APPENDIX I}

\section{ERROR ANALYSIS}

For each survey, each velocity stake was surveyed at least twice from each of the two survey stations. The $x, y$ and $z$ coordinates for each stake were taken as the mean of the values calculated from all the repeat surveys. The error associated with each coordinate was calculated as the standard deviation of this mean value. No additional instrument errors were included in calculations since these were significantly smaller than the measurement errors. Table 2 shows the mean error and the standard deviation of the mean error of the $x, y$ and $z$ coordinates for all stakes for all surveys.

The longitudinal velocity $\left(v_{x}\right)$ errors $\left(\right.$ in $\left.\mathrm{m} \mathrm{d}^{-1}\right)$ were calculated from

$$
x v e r r=\frac{\left(\sqrt{x \operatorname{coerr} 1^{2}+x \operatorname{coerr} 2^{2}}\right)}{t}
$$

where $x v$ err is the $v_{x}$ error, $x$ coerr 1,2 are the $x$ coordinate errors at surveys 1 and 2, respectively, and $t$ is the time in

Table 2. Average melt-season survey errors

\begin{tabular}{ccc}
\hline Coordinate & Average error & Std dev. error \\
& $\mathrm{mm}$ & $\mathrm{mm}$ \\
\hline$x$ & 17.5 & 11.4 \\
$y$ & 8.4 & 7.5 \\
$z$ & 11.4 & 6.9 \\
\hline
\end{tabular}

days between the two surveys; errors in $y$ and $z$ velocities are calculated similarly.

The errors in the strain rates stem from the measurement errors for coordinates of all three corners of each strain triangle for two consecutive surveys, and were calculated in two stages.

(1) A Monte Carlo simulation method was adopted whereby every $x$ and $y$ coordinate for every stake in each survey was considered to be the mean of a normal distribution of potential values for the coordinate, and the error of each coordinate was considered to represent the standard deviation of this normal distribution. This procedure assumes that if each stake had been surveyed far more often than it was, during each survey, then the standard deviation would be the same as for the actual four measurements upon which the error calculation is based. A hypothetical normal distribution of 100 values within 2.5 standard deviations of the mean (about 98\% of all potential values) was then constructed for every $x$ and $y$ coordinate.

(2) Strain-rate calculations were repeated 100 times for the entire strain network. Each time a different set of values was selected randomly from the hypothetical normal distributions for every $x$ and $y$ coordinate. The output from all 100 runs was stored. The final values of the output data were therefore calculated as the mean of 100 values. The errors associated with the data were taken as the standard deviations about the mean of these 100 values. The mean strain rates calculated by this method corresponded to those calculated from a single run using the mean values of the $x$ and $y$ coordinates. This procedure was considered to give a good estimation of the error in the strain-rate values. Table 3 shows the values of the average error and standard deviation of the average errors for all strain rates calculated.

The same method was used for calculating the propagation of error to the calculation of the components of the force budget. Table 4 shows the values of the average error and standard deviation of the average errors for all forcebudget components calculated.

\section{Table 3. Average strain-rate errors}

\begin{tabular}{ccc}
\hline Strain rate & $\begin{array}{c}\text { Average error } \\
\mathrm{a}^{-1}\end{array}$ & \multicolumn{1}{c}{ Std dev. error } \\
& $\mathrm{a}^{-1}$ \\
\hline$\dot{\varepsilon}_{x x}$ & 0.021 & 0.0058 \\
$\dot{\varepsilon}_{y y}$ & 0.015 & 0.012 \\
$\dot{\varepsilon}_{z z}$ & 0.028 & 0.013 \\
$\dot{\varepsilon}_{x y}$ & 0.019 & 0.006 \\
\hline
\end{tabular}

Table 4. Average force-budget component errors

\begin{tabular}{ccc}
\hline Force-budget component & $\begin{array}{c}\text { Average error } \\
\text { bar m }\end{array}$ & $\begin{array}{c}\text { Std dev. error } \\
\text { bar m }\end{array}$ \\
\hline$R_{x x}$ & 0.35 & 0.21 \\
$R_{x y}$ & 0.22 & 0.15 \\
$\tau_{\mathrm{b} x}$ & 0.44 & 0.29 \\
\hline
\end{tabular}




\section{Accounting for missing coordinate data}

The calculation of surface strain rates across the strain triangles requires a full set of $x$ - and $y$-coordinate data for all motion stakes for each of the two consecutive surveys. During some time periods, however, there were stakes for which coordinate data were not available for two consecutive surveys. Since the loss of one stake's continuous coordinate data can cause the loss of up to six strain triangles of strain-rate data, missing points were replaced with interpolated coordinate data. The method for determining coordinate data for "missing stakes" was as follows.

$20 \mathrm{~m} \times 20 \mathrm{~m}$ grids of surface $x$ and $y$ velocities were constructed across the entire area of the stake network using measured stake velocity data using the kriging interpolation routine of the program "Surfer" (Golden Software Inc.). Interpolated velocities for those points on the grid closest to the positions of missing stakes were recorded. Interpolated $x$ and $y$ coordinates were determined from these velocity values and from the coordinates at the start or end of the survey period, and used to calculate surface strain rates across all the strain triangles. For the time periods discussed in this paper the number of "missing stakes" was as follows: JD169-173, five; JD173-179, two; JD179-185, two.

\section{APPENDIX II}

\section{FORGE-BUDGET EQUATIONS}

Assuming that the upper boundary conditions of each of the hypothetical blocks of the glacier are a stress-free surface, then, after some manipulation (derived in full by Van der Veen and Whillans, 1989), the equations for the horizontal components of the force balance can be simplified to

$$
\begin{gathered}
\frac{\partial}{\partial x} \int_{b}^{h} R_{x x} \mathrm{~d} z+\frac{\partial}{\partial y} \int_{b}^{h} R_{x y} \mathrm{~d} z+\tau_{\mathrm{d} x}-\tau_{\mathrm{b} x}=0 \\
\frac{\partial}{\partial x} \int_{b}^{h} R_{x y} \mathrm{~d} z+\frac{\partial}{\partial y} \int_{b}^{h} R_{y y} \mathrm{~d} z+\tau_{\mathrm{d} y}-\tau_{\mathrm{b} y}=0,
\end{gathered}
$$

where $b$ is the elevation of the glacier bed, $\tau_{\mathrm{b} i}(i=x, y)$ is the basal drag, including all basal resistances, and the driving stress is calculated from

$$
\tau_{\mathrm{d} i}=-\rho g(h-b) \frac{\partial h}{\partial i} .
$$

A constitutive relationship between stresses and strain rates must be invoked to relate these stresses to observable strain rates. Constitutive relations generally link strain rates to deviatoric stresses rather than to full stresses or resistive stresses. Deviatoric stresses $\left(\sigma_{i j}{ }^{\prime}\right)$ are defined as full stresses minus the average normal stress

$$
\sigma_{i j}^{\prime}=\frac{\sigma_{i j}-\delta_{i j}\left(\sigma_{x x}+\sigma_{y y}+\sigma_{z z}\right)}{3} .
$$

Resistive stresses (Van der Veen and Whillans, 1989) can be expressed in terms of deviatoric stresses

$$
\begin{aligned}
& R_{x x}=2 \sigma_{x x}{ }^{\prime}+\sigma_{y y}{ }^{\prime} \\
& R_{x y}=\sigma_{x y}{ }^{\prime} .
\end{aligned}
$$

The constitutive relation used is that defined by Glen (1955) and Nye (1957) and reads

$$
\sigma_{i j}{ }^{\prime}=B \dot{\varepsilon}_{\mathrm{e}}{ }^{1 /(n-1)} \dot{\varepsilon}_{i j},
$$

where $B$ is the inverse flow-law parameter. The effective strain rate, $\dot{\varepsilon}_{\mathrm{e}}$, is calculated from

$$
\dot{\varepsilon}_{\mathrm{e}}^{2}=\frac{1}{2}\left(\dot{\varepsilon}_{x x}^{2}+\dot{\varepsilon}_{y y}^{2}+\dot{\varepsilon}_{z z}^{2}\right)+\dot{\varepsilon}_{x y}^{2}
$$

and describes the overall deformation rate and affects the relation between stress and strain rate such that an individual stress component acting by itself will produce a smaller strain than it would in the presence of other stresses.

Assuming no depth variation in strain rates, resistive stresses can therefore be calculated from the measured surface strain rates using

$$
\begin{aligned}
& R_{x x}=B \dot{\varepsilon}_{\mathrm{e}}{ }^{(1-n) / n}\left(2 \dot{\varepsilon}_{x x}+\dot{\varepsilon}_{y y}\right) \\
& R_{x y}=B \dot{\varepsilon}_{\mathrm{e}}^{(1-n) / n} \dot{\varepsilon}_{x y} .
\end{aligned}
$$

The balance of forces, $F_{x}$, acting on the vertical face of a column through each force-budget block, with a basal area of $1 \mathrm{~m}^{2}$, in the direction of the $x$ axis can be expressed as

$$
\begin{aligned}
F_{x}= & \frac{\left(H_{\mathrm{u}} R_{x x \mathrm{u}}-H_{\mathrm{d}} R_{x x \mathrm{~d}}\right)}{\Delta x}+\frac{\left(H_{\mathrm{w}} R_{x y \mathrm{w}}-H_{\mathrm{e}} R_{x y \mathrm{e}}\right)}{\Delta y} \\
& +\tau_{\mathrm{d} x}-\tau_{\mathrm{b} x}=0,
\end{aligned}
$$

where $H=h-b, \Delta x$ and $\Delta y$ are the average horizontal dimensions of each block and the subscripts ${ }_{\mathrm{u}}, \mathrm{d}$, w and $\mathrm{e}$ refer to the up-glacier, down-glacier, west and east sides of the block, respectively. 